\title{
Adhesión a dentina afectada por caries y dentina esclerótica
}

\author{
Ceballos García L*
}

\section{RESUMEN}

Se trata de formas de dentina alterada que son los substratos adhesivos más importantes clínicamente y menos receptivos a los tratamientos adhesivos que la dentina normal. Se describen la características histopatológicas y fisiológicas de: (1) dentina afectada por caries (ya sea en su capa superficial o en su capa profunda) y (2) dentina esclerótica. Se realiza una revisión de la literatura estudiando la adhesión a estos tipos de dentina.

Palabras clave: Adhesión, dentina afectada por caries y dentina esclerótica.

\section{ABSTRACT}

These are two kinds of dentin which are less receptive to adhesion and clinically more important than sound dentin. Their histopathological and physiological characteristics were described and a literature review was performed evaluating adhesion to these two kinds of altered dentin.

Key words: Adhesión, caries affected dentin, sclerotic dentin.

Aceptado para publicación: octubre 2003.

* Becaria Postdoctoral del Plan Progre de la Universidad de Valencia.

Ceballos García L. Adhesión a dentina afectada por caries y dentina esclerótica. Av. Odontoestomatol 2004; 20-2: 71-78.

La dentina, a diferencia del esmalte, es un tejido vital y dinámico, circunstancias que le permiten modificar su microestructura y composición como respuesta a procesos fisiológicos (edad, atricción), o patológicos, tales como la erosión, la abrasión, la abfracción o la caries.

Estas formas de dentina alterada que se originan son los substratos adhesivos más importantes clínicamente y, además, son menos receptivos a los tratamientos adhesivos que la dentina normal. Sin embargo, la mayoría de las investigaciones in vitro sobre adhesión se realizan utilizando especimenes de dentina sana y joven, procedente, en la mayoría de los casos, de premolares extraídos por motivos ortodóncicos y de terceros molares incluidos.

Este hecho ha condicionado que la mayor parte de la información de la que disponemos sobre la estructura dentinaria, su comportamiento como substrato adhesivo y las técnicas y procedimientos adhesivos vigentes en la actualidad se hayan descrito utilizando como modelo dentina sana. De ahí el interés en conocer las características histopatológicas de la dentina afectada por caries y la dentina esclerótica, que la diferencian de la dentina sana, para así entender la dificultad que presenta realizar un procedimiento adhesivo estable y duradero en estos substratos.

\section{DENTINA AFECTADA POR CARIES}

\section{Caries dentinaria}

El acierto en relacionar los hallazgos histopatológi- 




Fig. 1. Lesión cariosa en la que se observa una capa superficial de dentina infectada y otra más profunda de dentina afectada por caries.

cos y el comportamiento clínico frente a la caries dentinaria se lo debemos, sin lugar a dudas, al grupo de investigación dirigido por el Prof. Fusayama.

Ya en sus primeros trabajos llegaron a la conclusión de que el color y la dureza de la dentina cariada no se corresponden con su grado de deterioro por la invasión bacteriana, y, además, no son criterios fáciles de aplicar con precisión en clínica.

Del mismo modo, describieron que la caries dentinaria está formada por dos capas:
- Una capa superficial que está severamente descalcificada y no se puede remineralizar fisiológicamente. Esta capa la denominaremos también dentina infectada.

- Y una capa profunda en la que la descalcificación es moderada y a la que nos referiremos indistintamente como dentina afectada por caries.

Estos autores describieron en artículos posteriores que estas dos capas se pueden distinguir clínicamente por su tinción selectiva con fucsina básica al $0.5 \%$ en propilenglicol. La dentina afectada por caries no se tiñe con la fucsina, mientras que la infectada sí. Estas dos capas presentan, por tanto, características ultramicroscópicas, bioquímicas y fisiológicas diferentes.

\section{Capa superficial o capa de dentina infectada}

Se caracteriza porque la estructura histológica está completamente perdida. Los túbulos dentinarios están desorganizados y su interior está ocupado por bacterias que proliferan en su interior. Debido a la desmineralización que acompaña al proceso carioso la dentina peritubular desaparece y el diámetro tubular aumenta. Las bacterias van invadiendo la dentina intertubular, facilitado este hecho por la pérdida de la dentina peritubular, y los túbulos van coalesciendo unos con otros, dando lugar a la formación de áreas de necrosis. Otra vía de difusión bac-

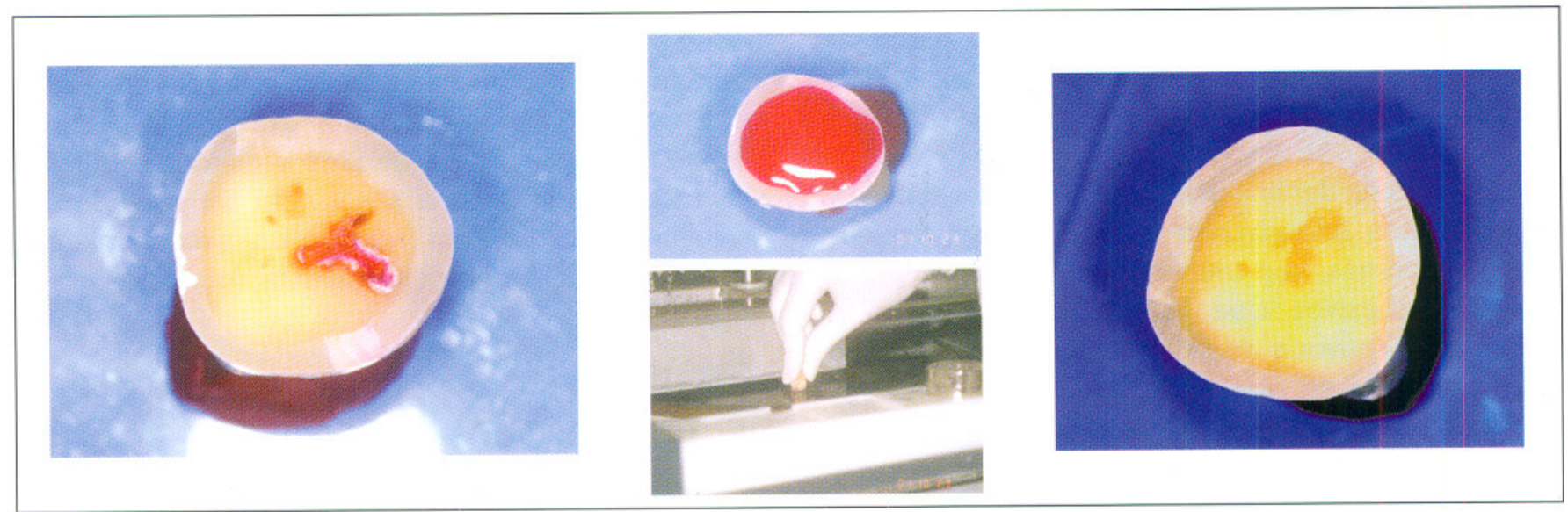

Fig. 2. 2a) Superficie dentinaria en la que se observa dentina sana, afectada por caries e infectada (teñida con fucsina). 2b) Tinción con fucsina. 2c) Pulido de la superficie dentinaria para eliminar la dentina infectada por caries. 2d) Misma superficie dentinaria en la que tras teñir con fucsina ya no se observa dentina infectada por caries, únicamente lesiones de dentina afectada rodeadas por dentina sana. 


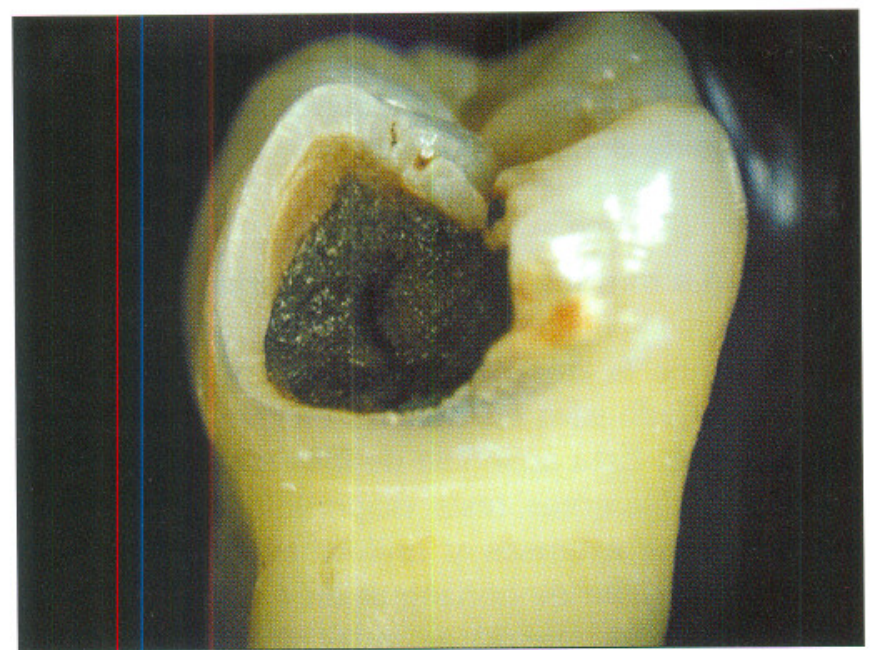

Fig. 3. Lesión cariosa muy extensa y con gran destrucción dentaria. La dentina presenta un aspecto necrótico.

teriana son las ramificaciones laterales de los túbulos dentinarios.

Junto a los túbulos llenos de bacterias se observan túbulos vacíos, en los que en su interior hay cristales granulares sueltos.

En la dentina intertubular se aprecia una desmineralización severa, las fibras de colágeno quedan expuestas total o parcialmente y están desnaturalizadas.

Estudios bioquímicos revelaron que los precursores del colágeno y los enlaces intermoleculares están dis-

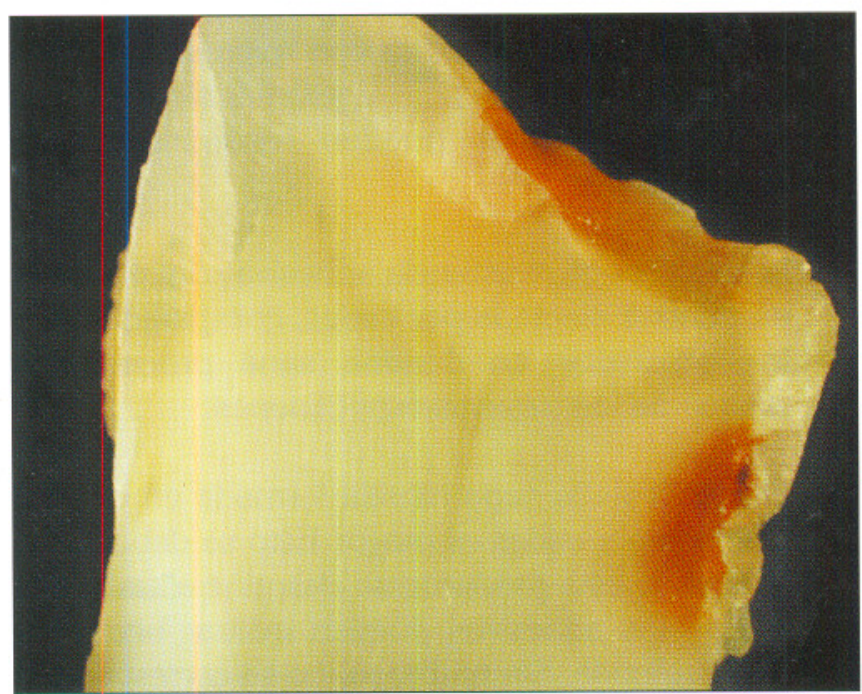

Fig. 4. Sección dentaria en la que se observan las distintas áreas de reacción de la capa de dentina afectada por caries. minuidos. Además, los cristales liberados son granulares y no guardan relación con la estructura orgánica. Dado que no hay procesos odontoblásticos vivos y las fibras colágenas están irreversiblemente dañadas, esta dentina no se puede remineralizar fisiológicamente, por lo que debe ser eliminada clínicamente.

Capa profunda o de dentina afectada por caries

Esta capa se puede dividir a su vez en tres áreas, teniendo todas en común que la estructura dentinaria está conservada:

- Capa túrbida.

- Zona transparente o translúcida.

- Zona subtransparente.

En la capa túrbida los procesos odontoblásticos están presentes y vivos. La dentina peritubular ya sí es evidente $y$, aunque la dentina intertubular está desmineralizada, las fibras colágenas no están desnaturalizadas y presentan sus bandas características. Estudios bioquímicos han puesto de manifiesto que los enlaces intermoleculares están reducidos, pero hay más precursores del colágeno. Otra característica es que los cristales de hidroxiapatita son más cortos, puesto que la desmineralización afecta en primer lugar a sus extremos.

Aunque se considera una capa libre de bacterias, hay autores que han demostrado su presencia.

En la zona transparente o translúcida, la dentina intertubular está también desmineralizada parcial-

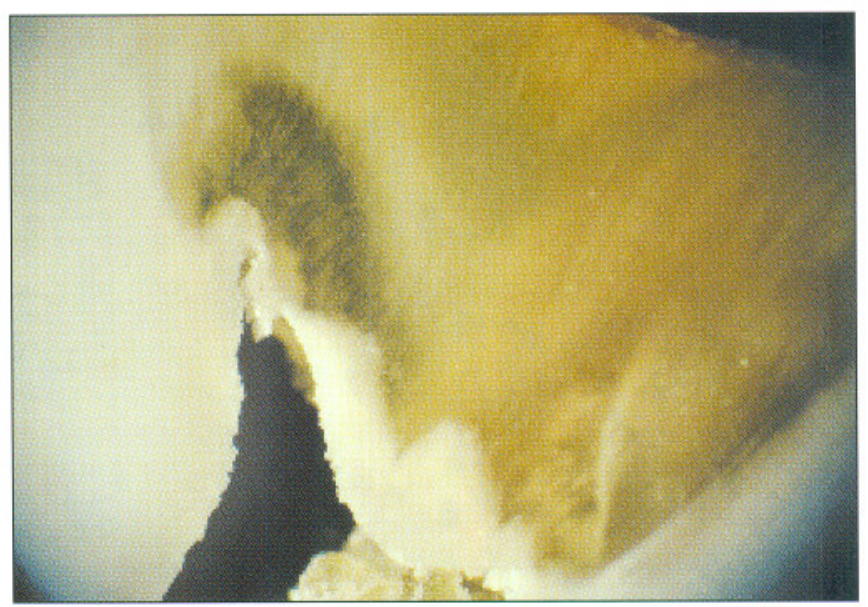

Fig. 5. Nótese la extensa zona de dentina transparente. 
mente. Hay una característica importante y es que los túbulos dentinarios están llenos de cristales de whitloquita. Estos cristales son de gran tamaño y más resistentes al ataque ácido. Esta esclerosis tubular es la responsable de su aspecto transparente o translúcido.

Los depósitos intratubulares no se sabe con certeza si son un mecanismo de defensa activo o el resultado de un fenómeno cíclico de disolución y precipitación de los cristales. Lo que sí se ha demostrado es que su presencia disminuye la permeabilidad dentinaria y, por tanto, el paso de ácidos, bacterias y productos bacterianos, sirviendo de protección para el tejido pulpar. Por estos motivos es una dentina que debemos respetar durante la remoción de la caries.

Algunos autores denominan a la dentina transparente dentina esclerótica, de hecho, clínicamente se describía como una dentina más dura a la exploración. Sin embargo, aunque el interior de los túbulos está ocupado por cristales de whitloquita, como ocurre en la dentina esclerótica, es una dentina significativamente más blanda. Esto se debe a que su matriz intertubular está desmineralizada como consecuencia del proceso carioso y, como ya ha sido demostrado, las propiedades mecánicas de la dentina dependen de las de la dentina intertubular.

Por último, la dentina subtransparente no es más que una zona de transición entre la zonza transpa-

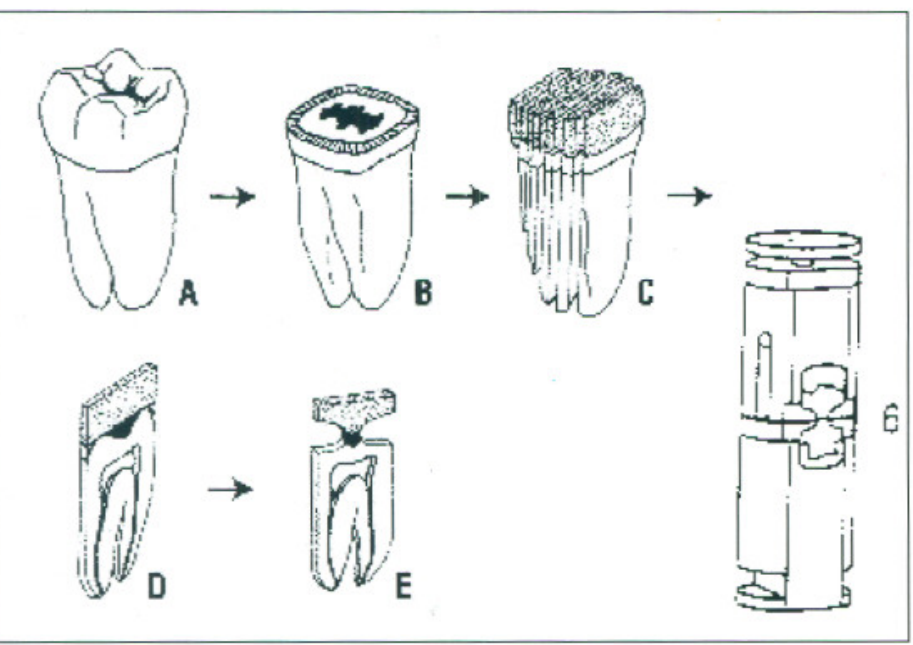

Fig. 6. Nakajima $M$ et al. Tensile bond strength and SEM evaluation or cariesaffected dentin using dentin adhesives. J Dent Res 1995; 74: 1679-1688. rente y la dentina sana subyacente, por lo que encontramos menos calcificaciones intratubulares y más áreas de dentina no afectada.

\section{Adhesión a dentina afectada por caries}

Si revisamos la literatura, los datos referentes a la resistencia adhesiva en dentina afectada por caries son escasos. Esta ausencia de información se debe a que los diferentes tests disponibles necesitaban evaluar áreas extensas y uniformes, circunstancia que es imposible de conseguir en dentina afectada por caries. El desarrollo de la técnica de microtensión permitió evaluar áreas adhesivas cercanas al milímetro cuadrado y, basándose en esta metodología, Nakajima pudo medir de forma selectiva la resistencia a la tensión en la dentina afectada por caries, áreas que se caracterizan por ser irregulares y pequeñas.

En sus diferentes estudios compararon la eficacia adhesiva obtenida con diferentes sistemas adhesivos en molares cariados, distinguiendo los valores obtenidos en la dentina afectada por caries y en la dentina sana procedente de un mismo espécimen. Para distinguir la dentina infectada de la afectada utilizaban fucsina básica y tras realizar el test de microtensión, determinaban la microdureza de cada espécimen para certificar si era o no dentina afectada. En sus estudios también observaron las características morfológicas de la interfase generada para cada tipo de adhesivo y dentina con microscopía electrónica de barrido. Los hallazgos más significativos de dichos estudios pueden resumirse de la siguiente forma:

- Los valores de resistencia adhesiva son inferiores en dentina afectada por caries, comparados con los obtenidos en dentina sana procedentes ambas de los mismos especimenes.

- El grosor de la capa híbrida formada en dentina afectada por caries es mayor. Esto se debe a que la dentina está previamente desmineralizada, por lo que los adhesivos pueden infiltrar una zona más profunda. Sin embargo, no se corresponden el grosor de esta capa con la resistencia adhesiva obtenida. 
- La microdureza de la dentina afectada por caries es siempre significativamente inferior a la de la dentina sana, a pesar de que los túbulos dentinarios estén obliterados por cristales minerales.

- Los autores recomiendan realizar una técnica de grabado total con ácido ortofosfórico en concentraciones entre el $32-37 \%$, puesto que consiguen remover de forma más efectiva los cristales intratubulares y, por tanto, mayor formación de tags de resina principales y laterales, que cuando utilizan concentraciones menores (10\%).

- Los resultados obtenidos ponen de manifiesto que la técnica de adhesión húmeda mejora la adhesión establecida no sólo en dentina sana, sino también en dentina afectada por caries.

- Las nuevas formulaciones de los sistemas adhesivos, como son los que se presentan en una solo frasco, aportan mejores valores de resistencia adhesiva tanto en dentina sana como en la afectada por caries.

- La información sobre la resistencia adhesiva obtenida con los sistemas autograbadores es aún insuficiente. Los autores describen que el grosor de la capa híbrida también está aumentado, por lo que esta dentina es también permeable a los monómeros ácidos, puesto que está previamente desmineralizada por el proceso carioso y es más porosa.

Las posibles causas que justifican los valores inferiores obtenidos en la dentina afectada por caries son:

- El colágeno de la dentina afectada puede estar alterado por el proceso carioso o por efecto del grabado ácido.

- La dentina afectada está desmineralizada per se, por lo que el frente de desmineralización tras el grabado es mayor y los adhesivos quizá no lo infiltren completamente. Este hecho supondría que quedara una zona de dentina desmineralizada sin infiltrar y, por tanto, sensible a la degradación hidrolítica.

- Por último, los depósitos intratubulares dificultan la penetración de los monómeros y, por tanto, la formación de tags de resina con hibridación de las paredes intratubulares y de las ramificaciones laterales.
De acuerdo con la mayoría de los autores, para conseguir una adhesión estable y duradera al tejido dentinario se ha de formar una capa híbrida no sólo en la dentina intertubular, sino también en las paredes de los túbulos, circunstancias todas ellas que estarían dificultadas o imposibilitadas en esta dentina afectada.

\section{DENTINA ESCLERÓTICA}

Estudios clínicos han puesto de manifiesto que las restauraciones de resina compuesta adheridas a dentina esclerótica o anciana muestran un porcentaje mayor de fracaso clínico. Esta dentina, que ha estado sometida a fenómenos de erosión, abrasión, atricción, abfracción o simplemente, como consecuencia del paso de los años, presenta una serie de características histopatológicas que condicionan este fracaso.

\section{Características histopatológicas de la dentina esclerótica}

La dentina esclerótica puede distinguirse visualmente utilizando la escala de Esclerosis dentinaria de Carolina del Norte:

Categoría 1: No hay esclerosis evidente, la dentina es opaca, de color amarillo claro o blanquecino sin alteración del color. Se aprecia una pequeña translucidez o transparencia.

Categoría 2: Existe una translucidez irregular que abarca menos del 50\% del área superficial.

Categoría 3: Las áreas irregulares translúcidas o transparentes ocupan más del $50 \%$ del área superficial.

Categoría 4: La dentina tiene una apariencia de cristal, de estar vitrificada, amarrilla oscura o con un color marronáceo, y la mayor parte de la dentina presenta translucidez o transparencia.

Al igual que la dentina afectada por caries, en la dentina esclerótica los túbulos dentinarios están obliterados por cristales de whitloquita, resistentes al ataque ácido, lo que condiciona que su permeabilidad 


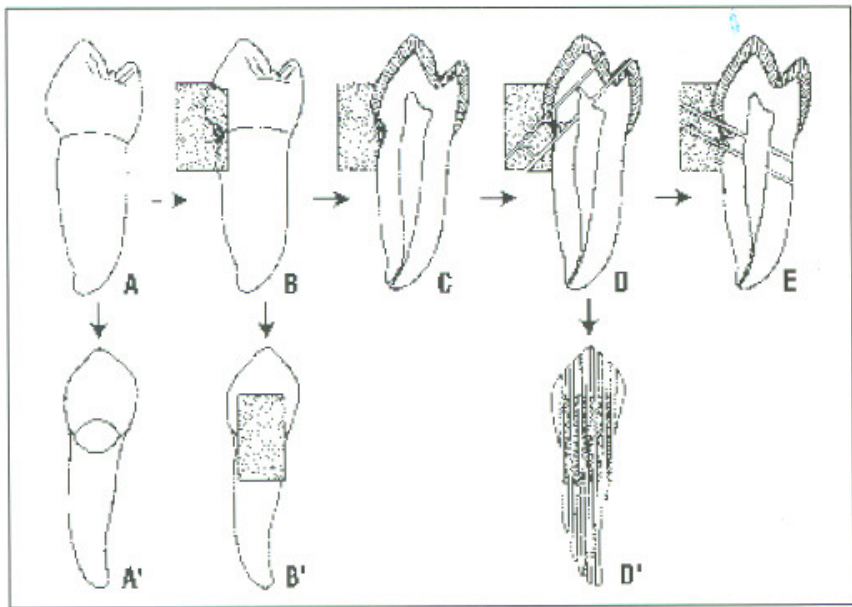

Fig. 7. Yoshiyama $M$ et al. Regional strengths of bonding agent to cervical sclerotic root dentin. J Dent Res 1996; 75: 1404-1413.

esté reducida. Sin embargo, la dentina intertubular no está desmineralizada, sino todo lo contrario y, por encima de esta área hipermineralizada, se aprecia una capa de bacterias.

\section{Adhesión a dentina esclerótica}

Los estudios que evalúan la resistencia adhesiva a esta forma de dentina alterada son escasos por los mismos motivos que fueron expuestos para la dentina afectada por caries. Y, al igual que ocurría con esta dentina, la modificación de la técnica de microtensión, en este caso por el Dr. Yoshiyama, permitió cuantificar la resistencia adhesiva en zonas de esclerosis.

Estos autores encontraron que los valores de resistencia adhesiva en dentina procedente de lesiones en cuña eran inferiores a los que obtenían en lesiones producidas artificialmente y achacaban este hecho a las características histológicas anteriormente descritas. La calcificación intratubular condicionaría la penetración intratubular de la resina adhesiva y la presencia de la capa hipermineralizada dificultaría la desmineralización y penetración posterior de la resina.

En cuanto a la morfología de la interfase generada en la dentina esclerótica, son muy interesantes los artículos de Prati y cols. y de Kwong y cols. Los autores describen que se produce una menor infiltración intratubular (tags de resina) por la presencia de cristales de whitloquita. Además, los tags de resina son anchos en sus primeras 3-4 micras, luego se estre- chan mucho y, generalmente, son más cortos, correspondiéndose con un efecto más superficial del grabado ácido debido a la hipermineralización. Por los mismos motivos, rara vez se observan tags laterales. La hipermineralización superficial de la dentina intertubular ocasiona que las capas híbridas que se forman sean más delgadas que en la dentina normal. Además, son muy irregulares en su espesor, puesto que la capa hipermineralizada y la de bacterias varían en su grosor según la localización, siendo más gruesas en la parte más profunda del defecto en cuña. En algunos casos las bacterias parecen sobrecrecimientos en la superficie de la capa hipermineralizada y otras muchas veces parecen ser parte integrante de la misma. A diferencia de lo que ocurre con las bacterias que integran el barrillo dentinario, las de la dentina esclerótica permanecen retenidas incluso después de grabar con ácido y lavar después profusamente.

Con el fin de mejorar los resultados de resistencia adhesiva diferentes autores han propuesto realizar modificaciones en la técnica adhesiva, denominadas por ellos "estrategias de adaptación":

1) Remover la capa más superficial con fresas: Esto supondría eliminar la zona hipermineralizada ácidoresistente. Sin embargo, algunos autores opinan que no reportaría ninguna ventaja puesto que produciríamos un barrillo dentinario también hipermineralizado, probablemente difícil de eliminar con el grabado ácido y de penetrar por los adhesivos autograbadores.

2) Aumentar el tiempo de aplicación de ácidos y primers autograbadores: Hay trabajos que han obtenido mejores resultados cuando aplican múltiples capas de autograbadores en la dentina esclerótica. El problema es que correríamos el riesgo de grabar en exceso la dentina sana adyacente, puesto que, como anteriormente hemos expuesto, el grosor de la dentina esclerótica es muy irregular.

Teniendo en cuenta lo anteriormente expuesto, podemos recomendar lo siguiente:

- Realizar de forma rutinaria la técnica de grabado total con ácido ortofosfórico en concentraciones entre el $32-37 \%$. Estudios clínicos han puesto de 
manifiesto que aunque la retención clínica es menor que en dentina sana, se considera aceptable.

- En cuanto a los adhesivos autograbadores, Kwong y cols. opinan que dados los resultados obtenidos quizá provean menor, o incluso una retención micromecánica inadecuada en la dentina esclerótica.

\section{BIBLIOGRAFÍA}

- Al-Salehi SK, Burke FJT. Methods used in dentin bonding tests: An analysis of 50 investigations on bond strength. Quintessence Int 1997; 28: 717-23.

- Duke ES y Lindemuth JS. Variability of clinical dentin substrates. Am J Dent 1991; 4: 241-6.

- Frank RM. Structural events in the caries process in enamel, cementum and dentin. J Dent Res 1990; 69: 559-66.

- Fusayama T, Okuse K, Hosoda H. Relationship between hardness, discoloration and microbial invasion in carious dentin. J Dent Res 1966; 45: 1033-1046.- Fusayama T y Terashima S. Differentiation of two layers of carious dentin by staining, Bull Tokyo Med Dent Univ 1972; 19: 8392.- Fusayama T. A simple pain-free adhesive restorative system by minimal reduction and total etching. Tokyo: ishiyaku EuroAmerica, 1993.

- Gwinnett J y Kanca J. Interfacial morphology of resin composite and shiny erosion lesions. Am J Dent 1992; 5: 315-7.

- Heymann HO, Sturdevant JR, Brunson WD, Wilder AD, Sluder TB, Bayne SC. Twelve-month clinical study of dentinal adhesives in class $\mathrm{V}$ cervical lesions. JADA 1988; 116: 179-83.

- Kinney JH, Balooch M, Marshall GW, Marshall SJ. A micromechanics model of the elastic properties of human dentine. Arch Oral Biol 1999; 44: 813822. - Kuboki Y, Ohgushi K, Fusayama T. Collagen biochemistry of the two layers of carious dentin. J Dent Res 1977; 56: 1233-7.
- Kwong S-M, Tay FR, Yip H-K, Kei L-H, Pashley DH. An ultrastructural study of the application of dentin adhesives to acid-conditioned sclerotic dentin. J Dent 2000; 28: 515-28.

- Llamas R, Jiménez-Planas A. Límite de la preparación cavitaria: Consideraciones clínicas e histopatológicas. Arch Odontoestomatol 1993: 501-12.

- Llamas Cadaval R, Sánchez-Barriga Mediero R, Bonilla Represa V, Herrera Martínez M, Pastor Conesa C. La caries, una enfermedad actual (y III). Características morfológicas de la caries dentinaria. Revista Europea de Odonto-Estomatología 2000; 12: 191-202.

- Marshall GW, Marshall SJ, Kinney JH, Balooch M. The dentin substrate: structure and properties related to bonding. J Dent 1997; 25: 441-458. Marshall GW, Habelitz S, Gallagher R, Balooch M, Balooch G, Marshall SJ. Nanomechanical properties of hydrated carious human dentin. J Dent Res 2001; 80: 1768-1771.- Marshall GW, Chang YJ, Gansky SA, Marshall SJ. Demineralization of caries-affected transparent dentin by citric acid: an atomic force microscopy study. Dent Mater 2001; 17: 45-52.

- Nakajima M, Sano H, Burrow MF, Tagami J, Yoshiyama M, Ebisu S, Ciucchi B, Russell CM, Pashley DH. Tensile bond strength and SEM evaluation of caries-affected dentin using dentin adhesives. J Dent Res 1995; 74: 1679-88.

- Nakajima M, Sano H, Zheng L, Tagami J, Pashley $\mathrm{DH}$. Effect of moist vs dry bonding to normal vs caries-affected dentin with Scotchbond MultiPurpose Plus. J Dent Res 1999; 78: 1298-1303.Nakajima M, Ogata M, Okuda M, Tagami J, Sano $\mathrm{H}$, Pashley DH. Bonding to caries-affected dentin using self-etching primers. Am J Dent 1999; 12: 309-314. - Nakajima M, Sano H, Urabe I, Tagami J, Pashley DH. Bond strength of Single-Bottle dentin adhesives to caries-affected dentin. Oper Dent 2000; 25: 2-10. - Ogata M, Nakajima M, Sano H, Tagami J. Effect of dentin primer application on regional bond strength to cervical wedge-shaped cavity walls. Oper Dent 1999; 24: 81-8. 
- Ogawa K, Yamashita Y, Ichijo T, Fusayama T. The ultrastructure and hardness of the transparent layer of human carious dentin. J Dent Res 1983; 62: 7-10. - Ohgushi K y Fusayama T. Electron microscopic structure of the two layers of carious dentin. J Dent Res 1972; 54: 1019-1026- Pashley EL, Talman R, Horner JA, Pashley DH. Permeability of normal versus carious dentin. Endodont Dent Traumatol 1991; 7: 207-211.Prati C, Chersoni S, Mongiorgi R, Montanari G, Pashley DH. Thickness and morphology of resininfiltrated dentin layer in young, old, and sclerotic dentin. Oper Dent 1999; 24: 66-72.

- Shimizu C, Yamashita Y, Ichijo T, Fusayama T. Carious change of dentin observed on longspan ultrathin sections. J Dent Res 1981; 60: 18261831.- Van Meerbeek B, Peumans M, Gladys S, Braem M, Lambrechts P, Vanherle G. Three-year clinical effectiveness of four total-etch dentinal adhesives systems in cervical lesions. Quintessence Int 1996; 27: 775-84.

- Yoshiyama M, Sano H, Ebisu S, Tagami J, Ciucchi B, Carvalho RM, Jonson MH, Pashley DH. Regional strengths of bonding agents to cervical sclerotic root dentin. J Dent Res 1996; 75: 1404-13.

- Yoshiyama M, Urayama A, Kimochi T, Matsuo T, Pashley DH. Comparison of conventional vs selfetching adhesive bonds to caries-affected dentin. Oper Dent 2000; 25: 163-9. 